\title{
Sympathetic Neural-Immune Interactions Regulate Hematopoiesis, Thermoregulation, and Inflammation in Mammals
}

\author{
Kelley S. Madden ${ }^{* a}$ \\ a Department of Biomedical Engineering, \\ School of Medicine and Dentistry, University of Rochester, Rochester, NY USA
}

\section{${ }^{*}$ Corresponding author:}

Kelley S. Madden, Ph.D.

University of Rochester Medical Center

Department of Biomedical Engineering

Goergen Hall; RC Box 270168

Rochester, NY 14627

E-mail: Kelley Madden@urmc.rochester.edu

Telephone: 585-273-5724

Fax: 585-276-2254 


\begin{abstract}
This review will highlight recently discovered mechanisms underlying sympathetic nervous system (SNS) regulation of the immune system in hematopoiesis, thermogenesis, and inflammation. This work in mammals illuminates potential mechanisms by which the nervous and immune systems may interact in invertebrate and early vertebrate species and allow diverse organisms to thrive under varying and extreme conditions and ultimately improve survival.
\end{abstract}




\section{INTRODUCTION}

In mammals, communication between the central nervous system (CNS) and

peripheral physiological systems is critical to survival in response to an external threat, such as an encounter with a predator. Equally important to survival is the ability to sense an internal threat, such as exposure to a pathogen. The CNS is closely involved in regulating the immune response to optimize the response to an internal threat. One of the unique features of the immune system is its mobility, and circulating immune cells are responsible for constant surveillance of the organism, signaling recognition of a foreign entity, and responding appropriately to eliminate a potentially dangerous pathogen. Bi-directional communication between the nervous system and immune system regulates the tempo, magnitude, and duration of the immune and inflammatory response to pathogen, to foreign antigens, and to injury. An important CNS outflow pathways in mammals mediating these neural-immune interactions is the sympathetic nervous system (SNS). The SNS is responsible for the 'fight or flight' response to threatening situations and consists of neural hard-wiring emanating from the spinal cord to innervate target organs, including primary and secondary lymphoid organs. Diverse stimuli (stressors, cytokines, infection), trigger the SNS and catecholamine release by nerves and by the adrenal medulla, leading to functional alterations in immune function that alter susceptibility to infection and other pathologies. The literature describing SNS innervation of primary (bone marrow and thymus) and secondary lymphoid organs (spleen and lymph nodes) and its impact on immune reactivity in mammals has been extensively reviewed (Bellinger and Lorton, 2014; Bellinger et al., 2008; Padro and Sanders, 2014). This review will highlight recent reports that illuminate the significance of neural-immune interactions in mammals and the 
underlying molecular mechanisms. These reports emphasize the role of catecholamines in fine-tuning inflammatory and immune responses. This fine-tuning is critical to maintaining homeostasis, and dysregulation of the communication between the nervous system and immune systems results in autoimmune disease, sepsis, and cancer progression (Cole et al., 2015; Padro and Sanders, 2014; Sternberg, 2006). Other major components of neuralimmune interactions, including the danger-sensing capabilities of afferent innervation of lymphoid organs and the immunomodulatory impact of the hypothalamic-pituitary-adrenal axis activation will not be discussed here. The interested reader is directed to excellent reviews (Bellinger and Lorton, 2014; Silverman and Sternberg, 2012; Sternberg, 2006).

The neurotransmitters of the SNS are the catecholamines norepinephrine (NE) and epinephrine (EPI). NE is released locally by sympathetic nerves and is the primary SNS effector in lymphoid organs. EPI is released by the adrenal gland into the blood stream to act by a humoral mechanism on target cells throughout the host. The production of catecholamines by cells of the immune system and the integration of non-neuronal sources of catecholamines in physiological responses will be discussed in more detail below. $\mathrm{NE}$ and EPI are the endogenous ligands for the adrenergic receptors (AR) consisting of $\alpha 1-\mathrm{AR}$, $\alpha 2$-AR, and 3 ß-AR subtypes, $ß 1, ß 2$, and $ß 3$. NE and EPI bind to AR subtypes with varying sensitivity. For example, EPI has higher affinity for ß2-AR compared to NE. AR expression by cells of the immune system has been well characterized (Padro and Sanders, 2014). AR expression, ligand affinity, and local ligand concentration determine the immune cell response elicited by SNS activation. 


\section{New Insights into SNS Interactions with the Immune System}

a. SNS regulation of hematopoietic stem cell mobilization from the bone marrow

Hematopoiesis is the creation of lymphoid and myeloid lineages from early multipotent stem cell progeny that have the capacity to differentiate into all blood cell lineages. A specialized bone marrow microenvironment, called the stem cell niche, is required for hematopoietic stem cell development and mobilization of newly differentiated lymphoid and myeloid cells into the circulation. Hematopoiesis is maintained under steady state conditions and is up-regulated under conditions that require greater output of stem cells, such as with chemo- or radiation cancer therapies (Katayama et al., 2006; MendezFerrer et al., 2008; Yamazaki et al., 2011). Recent research has demonstrated that SNS innervation is a critical regulator of hematopoiesis (Katayama et al., 2006; Mendez-Ferrer et al., 2010b)(reviewed in (Hanoun et al., 2015). In the stem cell niche, sympathetic nerves are associated with a highly specialized nestin-positive perivascular stromal cell population to form the neuroreticular complex (Frenette et al., 2013; Kunisaki et al., 2013; Mendez-Ferrer et al., 2010b; Yamazaki and Allen, 1990). This unit lies in close proximity to bone-lining osteoblasts and blood vessels to support hematopoietic stem cell activity and is the anatomical basis for sympathetic regulation of hematopoietic activity.

Frenette and colleagues have demonstrated that sympathetic input is critical to hematopoietic stem cell release, and have elucidated the underlying mechanisms. Under steady-state conditions, mobilized hematopoietic stem cells show a circadian rhythm with elevated circulating hematopoietic stem cell counts during periods of inactivity; highest in the morning for rodents, higher in the evening for humans (Lucas et al., 2008). Loss of sympathetic input by either chemical or surgical denervation prevented the steady-state 
circadian rhythmicity of circulating hematopoietic stem cells (Mendez-Ferrer et al., 2008) and attenuated G-CSF-induced hematopoietic stem cell mobilization (Katayama et al., 2006). Circadian rhythmicity was lacking in mice unable to express molecular clock genes, and B2-AR activation of the stromal cell population induced clock gene expression (Mendez-Ferrer et al., 2010a; Mendez-Ferrer et al., 2008), suggesting that sympathetic input maintains circadian rhythms under baseline conditions. Granulocyte-colony stimulating factor (G-CSF) facilitates hematopoietic stem cell release into the circulation by acting through CXCL12 and its receptor CXCR4 expressed by nestin+ perivascular stromal cells. In the absence of intact SNS signaling, a ß2-AR agonist elevated G-CSF-induced mobilization of hematopoietic stem cells and restored the deficiency in stem cell mobilization. It should be noted, however, that stimulation of SNS signaling in the absence of G-CSF did not elicit hematopoietic stem cell mobilization, suggesting that another unidentified G-CSF-induced mechanism is active in modulating and maintaining hematopoietic homeostasis. Interestingly, G-CSF decreased bone marrow NE levels, suggesting G-CSF regulates local NE release within the bone marrow (Katayama et al., 2006). This body of work demonstrates how non-immune cells (in this case, a mesencyhmal stromal cell population) may be incorporated as intermediaries in the interactions between the nervous and immune systems.

This new understanding of the critical role of bone marrow SNS innervation in steady-state and induced hematopoietic stem cell release has led to the proposal of new therapies for neoplasms associated with the bone marrow (Lucas et al., 2013). For example, B-AR agonists that stimulate G-CSF-induced hematopoietic stem cells may be used to increase hematopoietic stem cell yields after chemotherapy and for stem cell 
transplantation. Understanding the interactions between the SNS and immature immune and non-immune of the bone marrow will be beneficial for developing therapeutics that target local neural input in cancer and other diseases associated with hematopoiesis.

\section{b. SNS Regulation of Circulating Leukocytes}

Cells of the immune system constantly re-circulate to replace old and dying cells and to survey the environment for life-threatening pathogens or foreign antigen. Under homeostatic conditions, the entire pool of naïve T cells in a lymph node is replaced 2-3 times a day in the mouse, increasing the chance for antigen-specific naïve T cells to encounter its cognate antigen (Evans et al., 2015). Stimuli such as psychological stressors and exercise that activate the SNS regulate leukocyte migratory behavior (Dhabhar, 2002; Engler et al., 2004; Kruger et al., 2008; Viswanathan and Dhabhar, 2005). The SNS also appears to incorporate circadian rhythmicity into immune surveillance to provide optimal immune responsiveness when the animal is most active and has a greater likelihood of injury (Curtis et al., 2014; Mendez-Ferrer et al., 2008; Nguyen et al., 2013; Scheiermann et al., 2013; Scheiermann et al., 2012). Recent work has revealed a novel ß-AR-mediated mechanism that retains lymphocytes within lymph nodes.

Pharmacological and other stimuli that activate $B 2-A R$ elicit a rapid reduction in $B$ and T lymphocytes in the blood (lymphopenia) (Kruger et al., 2008; Nakai et al., 2014). Nakia and colleagues extended this finding by demonstrating that pharmacological ß2-AR activation also reduced lymphocytes within the lymph, suggesting that the emigration of lymphocytes from lymph nodes into lymph and blood was inhibited by ß2-AR activation (Nakai et al., 2014). Adoptive transfer studies demonstrated that $ß-A R$ stimulation of hematopoietic cells, most likely the T cells themselves, initiated this response. B2-AR 
activation of T cells induced a physical interaction between ß2-AR and chemokine receptors (CCR7 and CXCR4) that increased retention-promoting signals initiated through CCR7 and CXCR4. The clinical potential for this mechanism was demonstrated by the finding that ß2-AR-induced retention of autoreactive T cells within lymph nodes prevented the development of inflammation at distant sites (Nakai et al., 2014). Thus, direct AR stimulation of $\mathrm{T}$ cells regulate their retention and release from primary and secondary lymphoid organs via chemokine signaling mechanisms. These interactions between chemokines, chemokine receptors, and ß2-AR demonstrated in mammals raises the question whether such mechanisms may be present across the phyla. Chemokine families have been identified in birds, amphibians, fish, and lamprey (Bird and Tafalla, 2015; Chadzinska et al., 2014; Laing and Secombes, 2004). Less is known about chemokine influences in neural-immune interactions, but is actively being explored in teleosts (Kepka et al., 2013; Verburg-van Kemenade et al., 2011; reviewed in Verburg-van Kemenade et al., 2013).

c. Catecholamine thermoregulation: Links with Immune Activity

In mammals, endogenous production of heat energy by thermogenesis is necessary to maintain core body temperature in a cold environment and to elevate temperature in response to infection. During cold exposure, SNS activation and catecholamine release in adipose tissue is intimately involved with thermoregulation (Morrison et al., 2014). Several recent investigations have revealed links between thermoregulation, the SNS, and the immune system.

Standard rodent housing temperature of $72^{\circ} \mathrm{F}$ (between $20-26^{\circ} \mathrm{C}$ ) is below thermoneutral $\left(30^{\circ} \mathrm{C}\right)$ based on heat-seeking behaviors (Kokolus et al., 2013). In mammals, 
sub-thermoneutral temperatures are sensed by the hypothalamus, leading to SNS activation. Repalsky and colleagues demonstrated that cold exposure-induced sympathetic activation is associated with immunosuppression. Specifically, in tumor-bearing mice, standard housing temperature reduced anti-tumor CD8+ T cells and increased 2 immunosuppressive populations, myeloid derived suppressor cells and T regulatory cells in tumors compared to mice under thermoneutral conditions. Importantly, the immunosuppression observed under standard housing conditions was associated with increased tumor growth, and treatment with the ß-AR blocker propranolol restored tumor growth and the associated immune responses to that of mice raised under thermoneutral conditions (Eng et al., 2015; Kokolus et al., 2013). These results link thermoregulatory processes to immune reactivity, and may be clinically relevant in human cancer patients.

Another investigation revealed a novel link between thermoregulation, NE, and the immune system in adipose tissue. During cold exposure, normal mice maintain core body temperature by activation of adipocyte $B 3$-AR to induce lipolysis in white adipose tissue and expression of thermogenic genes in brown adipose tissue. These responses were blunted in IL-4\%/IL-13\%- mice. These mice lack a macrophage subset, the alternatively activated macrophages induced by IL-4 (Nguyen et al., 2011). In the IL4\%/IL13\% mice, direct $B 3-A R$ activation with a selective agonist restored the thermogenic response demonstrating that $ß 3-\mathrm{AR}$ responses were intact. These results suggested that macrophages participate in the adaptive response to cold exposure. Interestingly, NE was reduced in adipose tissue from Il4 \%/I113\% mice, and IL-4 exposure in vitro and in vivo increased expression of NE and the NE biosynthetic enzyme tyrosine hydroxylase in macrophages and induced fatty acid metabolism (Nguyen et al., 2011). These results 
demonstrate that macrophages in adipose tissue are a second source of NE, in addition to sympathetic nerves, for controlling thermogenesis. These results are consistent with the evidence that classically activated macrophages can also be a source of NE (Flierl et al., 2007), as discussed below.

These investigations indicate that the integration of neural-immune interactions with fat metabolism and thermoregulation is an important survival mechanism in mammals, and may be applicable in modulating immunity in vertebrates that hibernate. In invertebrates, a catecholamine response to heat stress has been demonstrated in hemocytes from scallops (Zhang et al., 2014) and in crickets, cuticle melanization and immune function appear to be linked with changes in environmental temperature and temperature (Adamo and Lovett, 2011; Fedorka et al., 2013).

\section{Neural Circuitry in Inflammation}

a. Inflammatory Reflexes

In mammals, the CNS receives information via neural and humoral mechanisms regarding the status of the peripheral immune system. These circuits are critical to regulate the response to a pathogen and to limit inflammation. The prototypical inflammatory reflex is suppression of endotoxin-induced production of TNF- $\alpha$ and is dependent on an intact vagus nerve. The sensory afferents involved in this vagal reflex are activated by receptors for TNF, IL-1, and other products of inflammation. These afferents project to regions in the CNS that produce the behavioral and physiological responses to infection and to acute and chronic immune responses, including sickness behavior and depression (Goehler et al., 2000; Goehler et al., 1999; Watkins et al., 1995). The efferent arm of this circuit is 
activation of the SNS leading to suppression of peripheral inflammation (Goehler et al., 1999; Watkins and Maier, 1999). This vagal reflex to endotoxin is dependent on the spleen, the presence of $\mathrm{T}$ cells (Rosas-Ballina et al., 2011), and the nicotinic acetylcholine receptor$\alpha 7$ subunit (Wang et al., 2003); reviewed in (Andersson and Tracey, 2012). The precise nature of the efferent component of this reflex is controversial, because stimulating the vagus does not induce firing of the splenic nerve and the spleen does not receive cholinergic innervation, as would be required for a true vagal reflex (Martelli et al., 2014; Nance and Sanders, 2007). In fact, direct stimulation of the splenic nerve suppresses inflammation, independent of the $\alpha 7$ nicotinic receptor subunit (Vida et al., 2011), and most likely through NE release and activation of macrophage ß-AR (Kees et al., 2003). Rosas-Ballina and colleagues have demonstrated that the source of acetylcholine is a $\mathrm{T}$ cell subset activated by ß2-AR to release acetylcholine that stimulates the macrophage nicotinic acetylcholine receptor $\alpha 7$ subunit to suppress TNF production (Rosas-Ballina et al., 2011). Thus an inflammatory response can be rapidly inhibited by the nervous system. The existence of this inflammatory reflex is indicative of the importance of returning inflammation to baseline. Inflammatory reflexes are involved in the regulation of acquired immune responses and influence disease progression from sepsis to arthritis (Andersson and Tracey, 2012; Deutschman and Tracey, 2014).

Direct stimulation of macrophage and dendritic cell AR by NE also regulates inflammatory processes. High concentrations of NE that activate ß-AR inhibits proinflammatory cytokine production by macrophages and dendritic cells (Hu et al., 2012; Kees et al., 2003). Dendritic cell ß2-AR activation in vitro reduced pro-inflammatory cytokine IL-6, IL-12, and IL-23 production and elevated production of the anti- 
inflammatory cytokine, IL-10 (Hu et al., 2012; Nijhuis et al., 2014). By contrast, lower levels of NE activate $\alpha$-AR to promote inflammation. Grebe and colleagues noted increased survival from intranasal influenza A infection in the absence of an intact SNS in conjunction with reduced lung monocytic infiltration and a significant reduction in pro-inflammatory cytokines. These effects were replicated with an $\alpha$-AR blocker, phentolamine, suggesting that $\mathrm{NE}$ acting on $\alpha$-AR-expressing target cells drove the inflammatory response in vivo (Grebe et al., 2010). In the lung and in arthritic joints, $\alpha$-AR activation promotes inflammation and exacerbates disease progression (Flierl et al., 2007; Pongratz and Straub, 2014). There is great potential to target AR to produce clinically significant improvement in inflammatory disease by limiting pro-inflammatory cytokines (Flierl et al., 2008; Pongratz and Straub, 2014).

Another aspect of the inflammatory reflex is local release of pro-inflammatory catecholamine neurotransmitters and sensory neuropeptides induced by inflammatory signals, such as endotoxin and IL-1ß acting on sympathetic and sensory nerves. The release of sensory neuropeptides such as corticotropin releasing hormone (CRH), substance P (SP), and calcitonin gene-related protein (CGRP) (review by (Deutschman and Tracey, 2014) triggers proinflammatory mediators that promote increased vasodilatation, blood flow, vascular leakiness, and pain. This response is down-regulated by gluococorticoids released by hypothalamic pituitary axis activation, another example of an inflammatory reflex that uses for its efferent arm the other major stress pathway in mammals (Sternberg, 2006).

\section{b. Non-neural sources of Neurotransmitters Regulate Inflammation}

In addition to neural-derived NE, macrophages, neutrophils, and lymphocytes can be sources of NE (reviewed by (Flierl et al., 2008)). Under inflammatory conditions in vitro, 
macrophages and neutrophils released NE along with up-regulation of catecholamine biosynthetic enzymes (Flierl et al., 2007). Under these conditions, blockade of $\alpha 2$-AR prevented the macrophage/neutrophil inflammatory response. This suggests that endogenous release of NE by macrophages and neutrophils feeds the inflammatory response via $\alpha 2$-AR activation (Flierl et al., 2007; Spengler et al., 1990). We can only speculate on the evolutionary forces that led to separate cellular sources of catecholamines, neural versus immune, in the regulation of immunity and inflammation. We suggest that catecholamines are critical components of an organism's threat-sensing system, capable of responding to external and internal stimuli via the nervous system and immune system, respectively. Neutrophils and macrophages are the first defenders to arrive at the site of injury or infection, and thus are well-suited to produce catecholamines required to finetune the subsequent inflammatory and immune response.

\section{Evidence for coordination between the nervous and immune systems throughout phylogeny}

Bi-directional communication between the immune and nervous systems in mammals is critical for fine-tuning of immune and inflammatory responses. The goal is to achieve a response sufficient to destroy a pathogen yet minimize normal tissue injury. The inability to eliminate a pathogen risks death; the inability to return an inflammatory

response to baseline underlies pathologies associated with sepsis, atherosclerosis, obesity, cancer and autoimmune diseases in mammals (Nathan and Ding, 2010). Given the survival benefits of neural-immune interactions, it is expected that such fine-tuning between the correlates of the nervous and immune systems may be active throughout phylogeny. 
Indeed, there is ample evidence that such communication may be evolutionarily conserved (Adamo, 2012). In invertebrates, threatening external and internal stimuli produce neurohormones and neurotransmitters that interact with the immune system, resulting in a survival advantage (Adamo, 2014; Adamo and Baker, 2011; Browne et al., 2014; Davis and Maerz, 2009; Denver, 2009, 2013; Peterson et al., 2013). Equivalents of the mammalian neurotransmitters acetylcholine, gamma-aminobutyric acid, NE, and other neuropeptides have been described in reflex neural circuits in invertebrate nematode worms (C. elegans) (Kawli et al., 2010; Komuniecki et al., 2014). In crickets, immune activation increased octopamine, a neurotransmitter correlate of NE in invertebrates, to elicit behavioral changes and alter immune function (Adamo, 2010, 2014). Stress-induced alterations in circulating hemocytes/leukocytes are present across the phyla under a variety of environmental conditions and in response to infection (Adamo, 2010; Browne et al., 2014; Falso et al., 2015; Kim and Kim, 2010; Renwrantz et al., 2013), including adaptation to cold in hibernation (Bouma et al., 2010; Sahdo et al., 2013). The neurohormonal mechanisms underlying these responses have not always been established, but it is likely that the neurotransmitter $\mathrm{NE}$ or its equivalents may be responsible. Understanding these mechanisms may illuminate the critical role for neural-immune interactions in organismal survival across phylogeny.

Acknowledgements: This work was supported by Department of Defense Breast Cancer Research Program (W81XWH-13-1-0439) and National Institutes of Health (R21 CA152777-01). 


\section{REFERENCES CITED}

Adamo, S.A., 2010. Why should an immune response activate the stress response? Insights from the insects (the cricket Gryllus texensis). Brain Behav Immun 24, 194200.

Adamo, S.A., 2012. The effects of the stress response on immune function in invertebrates: an evolutionary perspective on an ancient connection. Horm Behav $62,324-330$.

Adamo, S.A., 2014. The effects of stress hormones on immune function may be vital for the adaptive reconfiguration of the immune system during fight-or-flight behavior. Integr Comp Biol 54, 419-426.

Adamo, S.A., Baker, J.L., 2011. Conserved features of chronic stress across phyla: the effects of long-term stress on behavior and the concentration of the neurohormone octopamine in the cricket, Gryllus texensis. Horm Behav 60, 478-483.

Adamo, S.A., Lovett, M.M., 2011. Some like it hot: the effects of climate change on reproduction, immune function and disease resistance in the cricket Gryllus texensis. J Exp Biol 214, 1997-2004.

Andersson, U., Tracey, K.J., 2012. Neural reflexes in inflammation and immunity. J Exp Med 209, 1057-1068.

Bellinger, D.L., Lorton, D., 2014. Autonomic regulation of cellular immune function. Auton Neurosci 182, 15-41.

Bellinger, D.L., Millar, B.A., Perez, S., Carter, J., Wood, C., ThyagaRajan, S., Molinaro, C., Lubahn, C., Lorton, D., 2008. Sympathetic modulation of immunity: relevance to disease. Cell Immunol 252, 27-56. 
Bird, S., Tafalla, C., 2015. Teleost Chemokines and Their Receptors. Biology (Basel) 4, 756784.

Bouma, H.R., Strijkstra, A.M., Boerema, A.S., Deelman, L.E., Epema, A.H., Hut, R.A., Kroese, F.G., Henning, R.H., 2010. Blood cell dynamics during hibernation in the European Ground Squirrel. Vet Immunol Immunopathol 136, 319-323.

Browne, N., Surlis, C., Kavanagh, K., 2014. Thermal and physical stresses induce a shortterm immune priming effect in Galleria mellonella larvae. J Insect Physiol 63, 21-26.

Chadzinska, M., Golbach, L., Pijanowski, L., Scheer, M., Verburg-van Kemenade, B.M., 2014. Characterization and expression analysis of an interferon-gamma2 induced chemokine receptor CXCR3 in common carp (Cyprinus carpio L.). Dev Comp Immunol 47, 68-76.

Cole, S.W., Nagaraja, A.S., Lutgendorf, S.K., Green, P.A., Sood, A.K., 2015. Sympathetic nervous system regulation of the tumour microenvironment. Nat Rev Cancer 15, 563-572.

Curtis, A.M., Bellet, M.M., Sassone-Corsi, P., O'Neill, L.A., 2014. Circadian clock proteins and immunity. Immunity 40, 178-186.

Davis, A.K., Maerz, J.C., 2009. Effects of larval density on hematological stress indices in salamanders. J Exp Zoo. Part A, Ecological genetics and physiology 311, 697-704.

Denver, R.J., 2009. Stress hormones mediate environment-genotype interactions during amphibian development. Gen Comp Endocrinol 164, 20-31.

Denver, R.J., 2013. Neuroendocrinology of amphibian metamorphosis. Current topics in developmental biology 103, 195-227. 
Deutschman, C.S., Tracey, K.J., 2014. Sepsis: current dogma and new perspectives. Immunity 40, 463-475.

Dhabhar, F.S., 2002. Stress-induced augmentation of immune function--the role of stress hormones, leukocyte trafficking, and cytokines. Brain Behav Immun 16, 785-798.

Eng, J.W., Reed, C.B., Kokolus, K.M., Pitoniak, R., Utley, A., Bucsek, M.J., Ma, W.W., Repasky, E.A., Hylander, B.L., 2015. Housing temperature-induced stress drives therapeutic resistance in murine tumour models through beta2-adrenergic receptor activation. Nat Commun 6, 6426.

Engler, H., Dawils, L., Hoves, S., Kurth, S., Stevenson, J.R., Schauenstein, K., Stefanski, V., 2004. Effects of social stress on blood leukocyte distribution: the role of alpha- and beta-adrenergic mechanisms. J Neuroimmunol 156, 153-162.

Evans, S.S., Repasky, E.A., Fisher, D.T., 2015. Fever and the thermal regulation of immunity: the immune system feels the heat. Nat Rev Immunol 15, 335-349.

Falso, P.G., Noble, C.A., Diaz, J.M., Hayes, T.B., 2015. The effect of long-term corticosterone treatment on blood cell differentials and function in laboratory and wild-caught amphibian models. Gen Comp Endocrinol 212, 73-83.

Fedorka, K.M., Copeland, E.K., Winterhalter, W.E., 2013. Seasonality influences cuticle melanization and immune defense in a cricket: support for a temperaturedependent immune investment hypothesis in insects. J Exp Biol 216, 4005-4010.

Flierl, M.A., Rittirsch, D., Huber-Lang, M., Sarma, J.V., Ward, P.A., 2008. Catecholaminescrafty weapons in the inflammatory arsenal of immune/inflammatory cells or opening pandora's box? Mol Med 14, 195-204. 
Flierl, M.A., Rittirsch, D., Nadeau, B.A., Chen, A.J., Sarma, J.V., Zetoune, F.S., McGuire, S.R., List, R.P., Day, D.E., Hoesel, L.M., Gao, H., Van Rooijen, N., Huber-Lang, M.S., Neubig, R.R., Ward, P.A., 2007. Phagocyte-derived catecholamines enhance acute inflammatory injury. Nature 449, 721-725.

Frenette, P.S., Pinho, S., Lucas, D., Scheiermann, C., 2013. Mesenchymal stem cell: keystone of the hematopoietic stem cell niche and a stepping-stone for regenerative medicine. Ann Rev Immunol 31, 285-316.

Goehler, L.E., Gaykema, R.P., Hansen, M.K., Anderson, K., Maier, S.F., Watkins, L.R., 2000. Vagal immune-to-brain communication: A visceral chemosensory pathway. Auton Neurosci 85, 49-59.

Goehler, L.E., Gaykema, R.P.A., Nguyen, K.T., Lee, J.E., Tilders, F.J.H., Maier, S.F., Watkins, L.R., 1999. Interleukin- $1 \beta$ in immune cells of the abdominal vagus nerve: a link between the immune and nervous systems? J Neurosci 19, 2799-2806.

Grebe, K.M., Takeda, K., Hickman, H.D., Bailey, A.L., Embry, A.C., Bennink, J.R., Yewdell, J.W., 2010. Cutting edge: Sympathetic nervous system increases proinflammatory cytokines and exacerbates influenza A virus pathogenesis. J Immunol 184, 540-544. Hanoun, M., Maryanovich, M., Arnal-Estape, A., Frenette, P.S., 2015. Neural regulation of hematopoiesis, inflammation, and cancer. Neuron 86, 360-373.

Hu, Z., Chen, R., Cai, Z., Yu, L., Fei, Y., Weng, L., Wang, J., Ge, X., Zhu, T., Wang, J., Bai, C., 2012. Salmeterol attenuates the inflammatory response in asthma and decreases the pro-inflammatory cytokine secretion of dendritic cells. Cell Mol Immunol 9, 267275. 
Katayama, Y., Battista, M., Kao, W.M., Hidalgo, A., Peired, A.J., Thomas, S.A., Frenette, P.S., 2006. Signals from the sympathetic nervous system regulate hematopoietic stem cell egress from bone marrow. Cell 124, 407-421.

Kawli, T., He, F., Tan, M.W., 2010. It takes nerves to fight infections: insights on neuroimmune interactions from C. elegans. Dis Model Mech 3, 721-731.

Kees, M.G., Pongratz, G., Kees, F., Scholmerich, J., Straub, R.H., 2003. Via betaadrenoceptors, stimulation of extrasplenic sympathetic nerve fibers inhibits lipopolysaccharide-induced TNF secretion in perfused rat spleen. J Neuroimmunol $145,77-85$.

Kepka, M., Verburg-van Kemenade, B.M., Chadzinska, M., 2013. Neuroendocrine modulation of the inflammatory response in common carp: adrenaline regulates leukocyte profile and activity. Gen Comp Endocrinol 188, 102-109.

Kim, G.S., Kim, Y., 2010. Up-regulation of circulating hemocyte population in response to bacterial challenge is mediated by octopamine and 5-hydroxytryptamine via Rac1 signal in Spodoptera exigua. J Insect Physiol 56, 559-566.

Kokolus, K.M., Capitano, M.L., Lee, C.T., Eng, J.W., Waight, J.D., Hylander, B.L., Sexton, S., Hong, C.C., Gordon, C.J., Abrams, S.I., Repasky, E.A., 2013. Baseline tumor growth and immune control in laboratory mice are significantly influenced by subthermoneutral housing temperature. Proc Natl Acad Sci U S A 110, 20176-20181.

Komuniecki, R., Hapiak, V., Harris, G., Bamber, B., 2014. Context-dependent modulation reconfigures interactive sensory-mediated microcircuits in Caenorhabditis elegans. Curr Opin Neurobiol 29, 17-24. 
Kruger, K., Lechtermann, A., Fobker, M., Volker, K., Mooren, F.C., 2008. Exercise-induced redistribution of $\mathrm{T}$ lymphocytes is regulated by adrenergic mechanisms. Brain Behav Immun 22, 324-338.

Kunisaki, Y., Bruns, I., Scheiermann, C., Ahmed, J., Pinho, S., Zhang, D., Mizoguchi, T., Wei, Q., Lucas, D., Ito, K., Mar, J.C., Bergman, A., Frenette, P.S., 2013. Arteriolar niches maintain haematopoietic stem cell quiescence. Nature 502, 637-643.

Laing, K.J., Secombes, C.J., 2004. Chemokines. Dev Comp Immunol 28, 443-460.

Lucas, D., Battista, M., Shi, P.A., Isola, L., Frenette, P.S., 2008. Mobilized hematopoietic stem cell yield depends on species-specific circadian timing. Cell stem cell 3, 364366.

Martelli, D., McKinley, M.J., McAllen, R.M., 2014. The cholinergic anti-inflammatory pathway: a critical review. Auto Neurosci 182, 65-69.

Mendez-Ferrer, S., Battista, M., Frenette, P.S., 2010a. Cooperation of beta(2)- and beta(3)adrenergic receptors in hematopoietic progenitor cell mobilization. Ann N Y Acad Sci 1192, 139-144.

Mendez-Ferrer, S., Lucas, D., Battista, M., Frenette, P.S., 2008. Haematopoietic stem cell release is regulated by circadian oscillations. Nature 452, 442-447.

Mendez-Ferrer, S., Michurina, T.V., Ferraro, F., Mazloom, A.R., Macarthur, B.D., Lira, S.A., Scadden, D.T., Ma'ayan, A., Enikolopov, G.N., Frenette, P.S., 2010b. Mesenchymal and haematopoietic stem cells form a unique bone marrow niche. Nature 466, 829-834. Morrison, S.F., Madden, C.J., Tupone, D., 2014. Central neural regulation of brown adipose tissue thermogenesis and energy expenditure. Cell Metabolism 19, 741-756. 
Nakai, A., Hayano, Y., Furuta, F., Noda, M., Suzuki, K., 2014. Control of lymphocyte egress from lymph nodes through beta2-adrenergic receptors. J Exp Med 211, 2583-2598.

Nance, D.M., Sanders, V.M., 2007. Autonomic innervation and regulation of the immune system (1987-2007). Brain Behav Immun 21, 736-745.

Nathan, C., Ding, A., 2010. Nonresolving inflammation. Cell 140, 871-882.

Nguyen, K.D., Fentress, S.J., Qiu, Y., Yun, K., Cox, J.S., Chawla, A., 2013. Circadian gene Bmal1 regulates diurnal oscillations of Ly6C(hi) inflammatory monocytes. Science $341,1483-1488$.

Nguyen, K.D., Qiu, Y., Cui, X., Goh, Y.P., Mwangi, J., David, T., Mukundan, L., Brombacher, F., Locksley, R.M., Chawla, A., 2011. Alternatively activated macrophages produce catecholamines to sustain adaptive thermogenesis. Nature 480, 104-108.

Nijhuis, L.E., Olivier, B.J., Dhawan, S., Hilbers, F.W., Boon, L., Wolkers, M.C., Samsom, J.N., de Jonge, W.J., 2014. Adrenergic beta2 receptor activation stimulates antiinflammatory properties of dendritic cells in vitro. PLoS One 9, e85086.

Padro, C.J., Sanders, V.M., 2014. Neuroendocrine regulation of inflammation. Sem Immunol 26, 357-368.

Peterson, J.D., Steffen, J.E., Reinert, L.K., Cobine, P.A., Appel, A., Rollins-Smith, L., Mendonca, M.T., 2013. Host stress response is important for the pathogenesis of the deadly amphibian disease, Chytridiomycosis, in Litoria caerulea. PLoS One 8, e62146.

Pongratz, G., Straub, R.H., 2014. The sympathetic nervous response in inflammation. Arthritis Res Ther 16, 504. 
Renwrantz, L., Siegmund, E., Woldmann, M., 2013. Variations in hemocyte counts in the mussel, Mytilus edulis: similar reaction patterns occur in disappearance and return of molluscan hemocytes and vertebrate leukocytes. Comp Biochem Physiol. Part A, Molecular \& Integrative Physiology 164, 629-637.

Rosas-Ballina, M., Olofsson, P.S., Ochani, M., Valdes-Ferrer, S.I., Levine, Y.A., Reardon, C., Tusche, M.W., Pavlov, V.A., Andersson, U., Chavan, S., Mak, T.W., Tracey, K.J., 2011. Acetylcholine-synthesizing T cells relay neural signals in a vagus nerve circuit. Science 334, 98-101.

Sahdo, B., Evans, A.L., Arnemo, J.M., Frobert, O., Sarndahl, E., Blanc, S., 2013. Body temperature during hibernation is highly correlated with a decrease in circulating innate immune cells in the brown bear (Ursus arctos): a common feature among hibernators? Int J Med Sci 10, 508-514.

Scheiermann, C., Kunisaki, Y., Frenette, P.S., 2013. Circadian control of the immune system. Nat Rev Immunol 13, 190-198.

Scheiermann, C., Kunisaki, Y., Lucas, D., Chow, A., Jang, J.E., Zhang, D., Hashimoto, D., Merad, M., Frenette, P.S., 2012. Adrenergic nerves govern circadian leukocyte recruitment to tissues. Immunity 37, 290-301.

Silverman, M.N., Sternberg, E.M., 2012. Glucocorticoid regulation of inflammation and its functional correlates: from HPA axis to glucocorticoid receptor dysfunction. Ann N Y Acad Sci 1261, 55-63.

Spengler, R.N., Allen, R.M., Remick, D.G., Strieter, R.M., Kunkel, S.L., 1990. Stimulation of alpha-adrenergic receptor augments the production of macrophage-derived tumor necrosis factor. J Immunol 145, 1430-1434. 
Sternberg, E.M., 2006. Neural regulation of innate immunity: a coordinated nonspecific host response to pathogens. Nat Rev Immunol 6, 318-328.

Verburg-van Kemenade, B.M., Ribeiro, C.M., Chadzinska, M., 2011. Neuroendocrineimmune interaction in fish: differential regulation of phagocyte activity by neuroendocrine factors. Gen Comp Endocrinol 172, 31-38.

Verburg-van Kemenade, B.M., Van der Aa, L.M., Chadzinska, M., 2013. Neuroendocrineimmune interaction: regulation of inflammation via G-protein coupled receptors. Gen Comp Endocrinol 188, 94-101.

Vida, G., Pena, G., Deitch, E.A., Ulloa, L., 2011. alpha7-cholinergic receptor mediates vagal induction of splenic norepinephrine. J Immunol 186, 4340-4346.

Viswanathan, K., Dhabhar, F.S., 2005. Stress-induced enhancement of leukocyte trafficking into sites of surgery or immune activation. Proc Natl Acad Sci U S A 102, 5808-5813.

Wang, H., Yu, M., Ochani, M., Amella, C.A., Tanovic, M., Susarla, S., Li, J.H., Wang, H., Yang, H., Ulloa, L., Al-Abed, Y., Czura, C.J., Tracey, K.J., 2003. Nicotinic acetylcholine receptor alpha7 subunit is an essential regulator of inflammation. Nature 421, 384388.

Watkins, L.R., Goehler, L.E., Relton, J.K., Tartaglia, N., Silbert, L., Martin, D., Maier, S.F., 1995. Blockade of interleukin-1 induced hyperthermia by subdiaphragmatic vagotomy: evidence for vagal mediation of immune-brain communication. Neurosci Lett 183, 27-31.

Watkins, L.R., Maier, S.F., 1999. Implications of immune-to-brain communication for sickness and pain. Proc Natl Acad Sci U S A 96, 7710-7713. 
Yamazaki, K., Allen, T.D., 1990. Ultrastructural morphometric study of efferent nerve terminals on murine bone marrow stromal cells, and the recognition of a novel anatomical unit: the "neuro-reticular complex". Am J Anatom 187, 261-276.

Yamazaki, S., Ema, H., Karlsson, G., Yamaguchi, T., Miyoshi, H., Shioda, S., Taketo, M.M., Karlsson, S., Iwama, A., Nakauchi, H., 2011. Nonmyelinating Schwann cells maintain hematopoietic stem cell hibernation in the bone marrow niche. Cell 147, 1146-1158.

Zhang, H., Zhou, Z., Yue, F., Wang, L., Yang, C., Wang, M., Song, L., 2014. The modulation of catecholamines on immune response of scallop Chlamys farreri under heat stress. Gen Comp Endocrinol 195, 116-124. 


\section{Figure Legend}

Fig. 1. Sympathetic neural-immune interactions are bi-directional. External stimuli detected by the central nervous system are communicated to the periphery in part via the neural hard-wiring of the sympathetic nervous system. Norepinephrine (NE) released by sympathetic nerves within target tissues, such as bone marrow, adipose tissue, and lymphoid organs regulate hematopoiesis, fat metabolism, and surveillance by the immune system. Upon detection of a pathogen or injury, the SNS regulates the immediate inflammatory processes and subsequent innate and acquired immune responses. Pathogen exposure, wounding, or activation of the immune system are communicated to the central nervous system via humoral mechanisms and neural afferents with the goal of achieving the appropriate response to eliminate the pathogen, repair the wound, and to return all systems to baseline. Recent work demonstrates that in addition to nervous system release of NE, cells of the immune system may provide non-neural sources of NE to locally regulate thermogenesis and immune/inflammatory responses. 


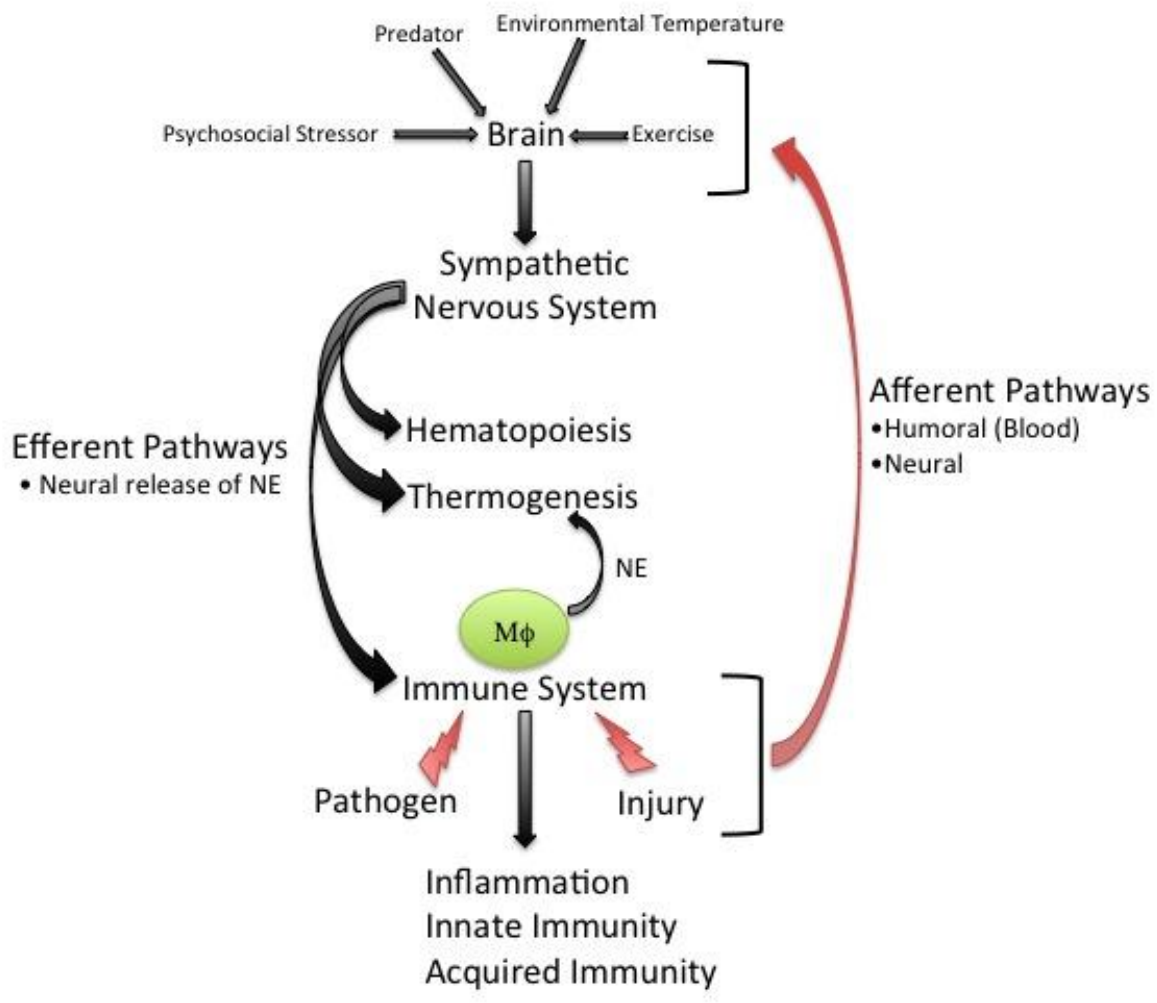

